\title{
The Growth of Mathematical Knowledge
}

\section{Edited by Emily Grosholz and Herbert Breger}

Dordrecht: Kluwer Academic Publishers, 2000.

Philosophical study of the growth of mathematics looks to history rather than formal logic. This is not merely because immature knowledge tends to be conceptually unclear and therefore unsuitable for formalisation. Indeed, a field of mathematical research could be immature and yet be populated by perfectly clear and fully-formalised mathematics. The point, rather, is that the process through which mathematics develops evades formalisation, even if the mathematics itself does not. Thus history, which studies processes rather than objects and their relations, is the appropriate tool. Moreover, historical case-studies can alleviate the worry that philosophers have directed almost all of their attention at the 'foundational' subdisciplines of logic and set-theory, leaving the rest of mathematics neglected. (In practice, philosophical attention to the history of mathematics tends to concentrate on a few favoured topics, so the increase in scope is not as great as might have been hoped).

Philosophical interest in the growth of mathematics has been rising in recent decades, facilitated and inspired by the emergence of university departments and journals devoted to the history and philosophy of science. Nevertheless this remains a small field, constrained by the difficulty of interdisciplinary research and a shortage of suitable journals in which to publish. Consequently, work in this area has been sporadic and of mixed quality. This collection of high-quality philosophical and historical essays is, therefore, timely. Indeed, Emily Grosholz, in her editorial introduction, makes a stronger claim than this: the established tradition in the philosophy of mathematics has, she says, been falling into crisis. The use of formal logic to investigate the nature and foundations of mathematical knowledge "has exhausted many of its original possibilities and failed to attract renewed support from working mathematicians" (p. xii). Increasing numbers of young philosophers study mathematics through its history rather than with formal logic (though this increase starts, it must be said, from a low base). Normative philosophy of science needed Kuhn to rouse it from its ahistorical slumbers. According to Grosholz, the philosophy of mathematics is on the verge of a similar (though, let us hope, less rude) awakening. Fortunately we do not need to evaluate this stronger claim to see the worth of this collection.

Multi-author volumes, at their worst, can be no more than a loose collection of quite disparate papers. Editors often seem to have persuaded their authors to contribute by offering them a licence to interpret the title of the collection however they wish. The list of contributors to a collection too often reads like an informal meeting of the editor's academic chums - understandably, for who else can one ask to donate a paper to yet another anthology? Or, if the authors are diverse, the literature they address may not be. But this book suffers none of these defects.

The structure of the collection no doubt reflects the organisation of the conference that gave rise to it. The contents are divided first into three parts. Part One, consisting of eleven essays, is misleadingly titled 'The Question of Empiricism'. In fact (with the exception of a paper on empiricist philosophy of mathematics by Donald Gillies) empiricism has little to do with it. The sub-title makes this clear: 'The role of scientific theory and empirical fact in the growth of mathematical knowledge'. 
Part Two (also eleven essays) is called 'The Question of Formalism: the role of abstraction, analysis and axiomatisation in the growth of mathematical knowledge'. Part Three (six essays) is 'The Question of Progress: criteria for the characterisation of progress in mathematical knowledge'.

Grosholz, in her editorial introduction, explains that each of the first two parts consists of four philosophical essays, each of which is followed by related historical case studies. On the face of it this organisation suggests a simple model of the relationship between history and philosophy, in which general philosophical theses are opposed with counterexamples drawn from history. In other words: philosophy proposes, history disposes. The first two discussions do indeed have that form.

Jaakko Hintikka and Donald Gillies offer philosophical views of mathematics that are, respectively, inductivist and empiricist. These then suffer severe, perhaps fatal, criticism in the form of counterexamples offered by historians Michael Mahoney and Ivo Schneider. Fortunately, this dispiriting pattern does not persist beyond the first two discussions. This may be because most of the other philosophers in the collection are not so heavily burdened with general philosophical views to which their ruminations on mathematics must conform. Elsewhere in the collection, historians use their grasp of detail to illustrate or qualify philosophical proposals that are historically sensitive to begin with. Often the role of the historical case-studies is simply to balance the abstraction of philosophy with a reminder of the richness of the historical record.

The division into three parts breaks down rather-for example, Herbert Breger, Grosholz's co-editor, contributes a paper called ' Tacit Knowledge and Mathematical Progress'. In it he argues that formalisation often articulates a previously tacit feeling for the domain in question. Recognition of this tacit grasp of the subject-matter may remove the appearance of arbitrariness or magic that might otherwise attach to a formalising move. In this sense, formalisation may represent progress in knowledge rather than the mere proliferation of systems. Breger's paper sits in Part Two ('The Question of Formalism'), but much of the subsequent discussion considers the nature of progress in mathematics, and might just as well occur in Part Three. The next discussion starts with Hourya Benis-Sinaceur's paper 'The Nature of Progress in Mathematics: The Significance of Analogy'. This occurs in Part Two because it argues that "model theory has transformed logic into an art of invention" (p. 291), and is therefore concerned with the heuristic benefits of a certain sort of formalisation. Nevertheless, this paper (and the subsequent discussion) is also about progress, and could have appeared in Part Three. Therefore, the division between parts Two and Three is almost arbitrary. The editors would no doubt reply that any division of a field of enquiry into topics must allow some overlap. However, this project seems to have developed its own shape, different from the structure that the editors originally planned for it. It is a pity (but by no means a fatal flaw) that the editors did not re-organise the book to reflect this evolution.

The contributors are drawn from twelve countries and include many famous names. The historical cases are almost all found in modern (that is to say, postrenaissance) European mathematics (though there is some brief discussion of ancient Greek and Chinese mathematics). This apparent narrowness is defensible because contemporary mathematics is almost all based on the European tradition. Examples drawn from medieval Indian mathematics or Japanese temple geometry would score points for cultural diversity without adding anything to our philosophical understanding of the mathematics that matters to us here and now. Moreover, the 
range of examples within the modern European tradition is broad. The history of analysis does not dominate, as one might have feared.

The dust-jacket announces that this book is "inspired" by Hilbert, Wittgenstein, Cavaillès and Lakatos. Fortunately, this inspiration is indirect and not at all doctrinaire. No-one sets out to prove that any of these luminaries was simply right about mathematics. Indeed, Wittgenstein, Cavaillès and Lakatos are hardly mentioned at all. Their contribution is, presumably, to draw philosophical attention to the history and practice of mathematical research. Having done so, they can depart the scene. Hilbert, as the only notable mathematician in the quartet, receives rather more attention. In his case, we have to take it that he inspired the accent on formalisation, though the discussion thereof does not emphasise his work as one might have expected, given his 'inspirational' status. Nor should it be thought that a single theoretical orientation prevails. Indeed, one thing lacking is any consideration of the relationships between philosophy and history. For example, some contributors want to move from a discussion of the growth of mathematical knowledge to the question of realism. But it is arguable that a study of historical processes cannot help with this latter. First, history studies datable, concrete processes, and second, the growth of mathematical knowledge falls within the scope of human experience. To address the question of realism we have to ignore both these restrictions. These considerations are not, as they stand, decisive. They are offered here to suggest the sort of second-order issues that interdisciplinary research throws up.

The book lacks an index, but this and the other complaints mentioned here are minor. There are very few typographical errors. Authors do not seem to have been discouraged from including diagrams. The print and paper are of high quality. Overall it is a rich and thought-provoking contribution to a relatively undeveloped area of research. Indeed, the philosophy of the growth of mathematical knowledge has few canonical texts as yet. This book may become one. 